\title{
The fatigue design of welded structure based on hydraulic bracket
}

\author{
Gao Youjin $^{1}$, Li Zheng ${ }^{1}$, Zhao Xiaohui ${ }^{1,2, a,{ }^{*}}$, Fan Yanjun ${ }^{2}$ \\ ${ }^{1}$ Zhengzhou Coal Mining Machinery Group Company Limited, Zhengzhou, 450016, China \\ ${ }^{2}$ Key Laboratory of Automobile Materials, School of Materials Science and Engineering, Jilin \\ University, Changchun 130025, China \\ azhaoxiaohui@jlu.edu.cn \\ ${ }^{*}$ Corresponding author
}

Keywords: Hydraulic bracket; Weld; Fatigue; Stress concentration

\begin{abstract}
As the main supporting equipment of the fully mechanized coal system, hydraulic bracket bears complex alternating load. The fatigue failure of welded structure as the main part of hydraulic bracket often occurs. In this paper, based on the welded structure of hydraulic bracket, the design methods and the life prolonging measures which are helpful to improve the life of hydraulic bracket were discussed.
\end{abstract}

\section{Introduction}

As the main energy, coal is under development and utilization completely in the whole world. Mining efficiency and security is the key of coal resource utilization. Hydraulic bracket is the main supporting equipment of comprehensive mechanized coal mining system. Its development level is an important symbol of the development level of coal machine equipment.

In recent years, with the rapid development of mining technology in China as well as effective demand of large mine and requirement of strong support, hydraulic bracket is developing toward the high-end and super high-end direction. Now, the service life of domestic high-end hydraulic bracket is about 40000 times. In the future, the requirement of high service life level of domestic high-end hydraulic bracket will be higher, even up to 80000-100000 cycles. This great leap forward development will bring many new challenges to the research field of hydraulic bracket, but the key technical problem is the fatigue life extension of high reliability hydraulic bracket structure ${ }^{[1,2]}$.

The working process of hydraulic bracket has very complex dynamic characteristics. Its working process bears with large dynamic load. The main failure mode is fatigue failure. Welding is the essential connection technology among the manufacturing process of hydraulic bracket structure. Welding joint is more sensitive to fatigue failure than base metal. According to the observation, it is observed that structure failure of the welding is caused by fatigue failure of welded joints. Thus, we need to rely on the fatigue performance of welding joints to design the fatigue strength of welding structural $^{[3-5]}$. This has important meaning for the development of hydraulic bracket.

\section{The stress analysis with the overall structure of hydraulic bracket}

The main body of welding structure of hydraulic bracket is box type structure, and also includes part of butt-jointed seam. Because of its smaller stress concentration, butt-jointed seam (weld root has been treated and has no stress concentration) is the best of all weld seams. But the box type structure is mainly composed of fillet weld seam. Fillet weld seam has serious stress concentration and deformation. It is the weak position which will affect the service life of the whole structure.

According to the general principles of fatigue design, we need to take the stress analysis with the overall structure of hydraulic bracket, and then get the weak position of hydraulic bracket when it is in working stress state. Fig. 1 is the stress nephogram when the overall structure of hydraulic bracket is under stress. According to the stress nephogram, we know that stress concentration exists at the position of fillet weld seam of the top beam and the base. Especially, the fillet weld seam of the main 
reinforcement and roof panel, bottom plate is more likely to happen to fatigue failure. Thus, the form and detail of fillet weld seam should be improved.

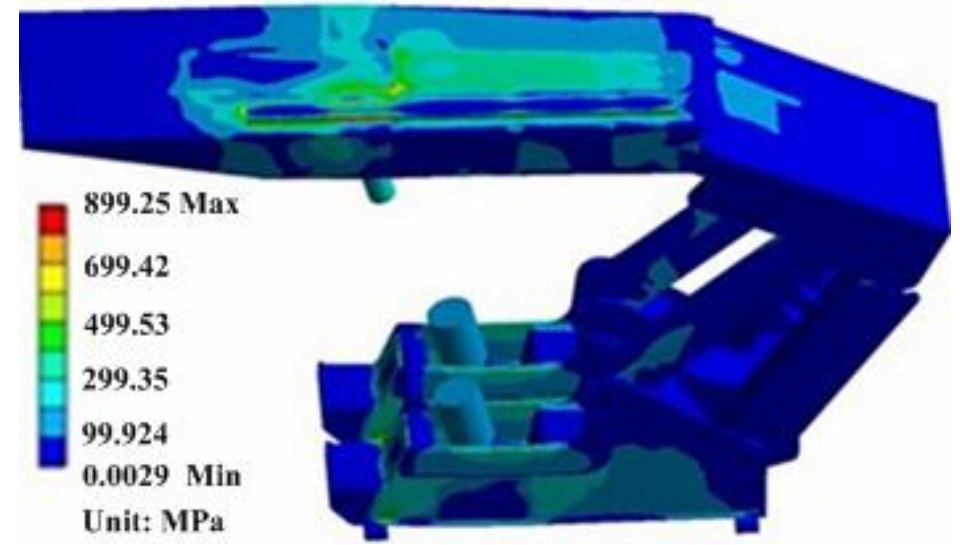

Fig. 1. Mises stress nephogram of the whole frame when the top beam is subjected to eccentric load and both ends of the base are on stress

Fig. 2 is the form of joint before and after improvement. We insist on the principle of saving welding materials in the process of improvement.

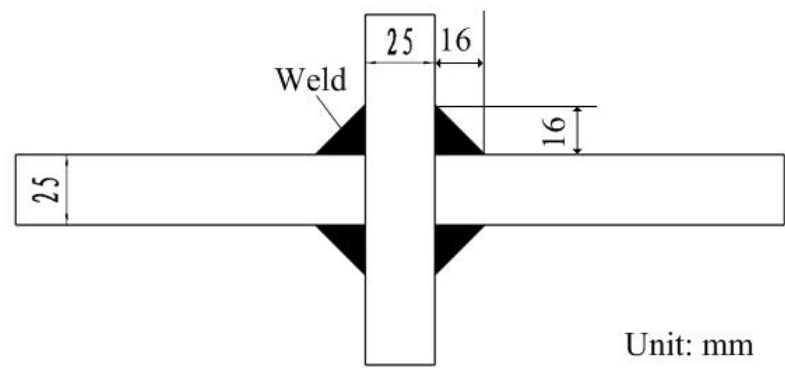

(a) Before improvement

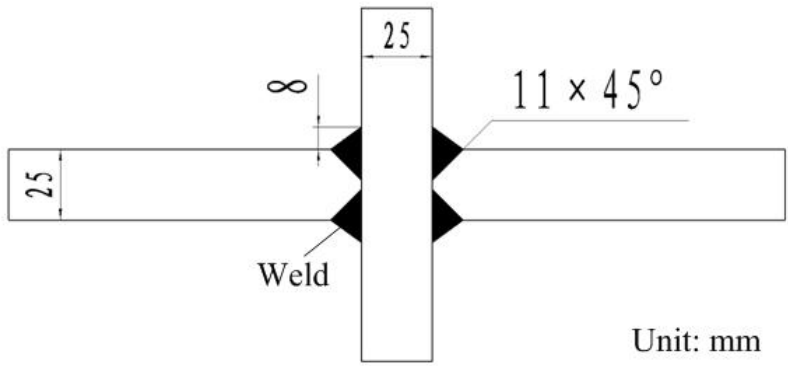

(a) After improvement

Fig. 2. The form of joint before and after improvement.

Fig. $2 \mathrm{~b}$ shows that the weld metal of the opened groove joint is less than unopen groove joint. At the same time, the effective cross-sectional area of the joint before improvement is close to the joint after improvement through the full penetration treatment.

\section{Results and discussion}

The main structure of hydraulic bracket is box type structure. Conducting the directly fatigue test of the whole box type structure is impossible. In order to take fatigue test conveniently, the cross joint to simulate box structurewe was used. One side of the cross joint is in accordance with the characteristics of box type structure. At the same time, the cross joints can be sandwiched conveniently, so we can finish the fatigue test smoothly. The base metal in this experiment is Q690 steel. The thickness of the steel plate is $25 \mathrm{~mm}$. Welding material is gas shielded welding whose trademark is GHS-60.

The high frequency fatigue testing machine was used to take fatigue tests on opened groove joints and unopened groove joints. For each type of groove, five stress levels were carried out. Fig. 3. is the fatigue $S-N$ curve of opened groove joints and unopened groove joints.

From Fig. 3 we know that the fatigue strength of the unopened groove joint is about $203 \mathrm{MPa}$ corresponding to $10^{5}$ cycles and $96 \mathrm{MPa}$ corresponding to $10^{6}$ cycles. However, the fatigue strength of the opened groove joint is about $385 \mathrm{MPa}$ corresponding to $10^{5}$ cycles and $239 \mathrm{MPa}$ corresponding to $10^{6}$ cycles. Compared to the unopened groove joint, fatigue strength of the opened joint increased by $76.4 \%$ corresponding to $10^{5}$ cycles and $148.9 \%$ corresponding to $10^{6}$ cycles. 


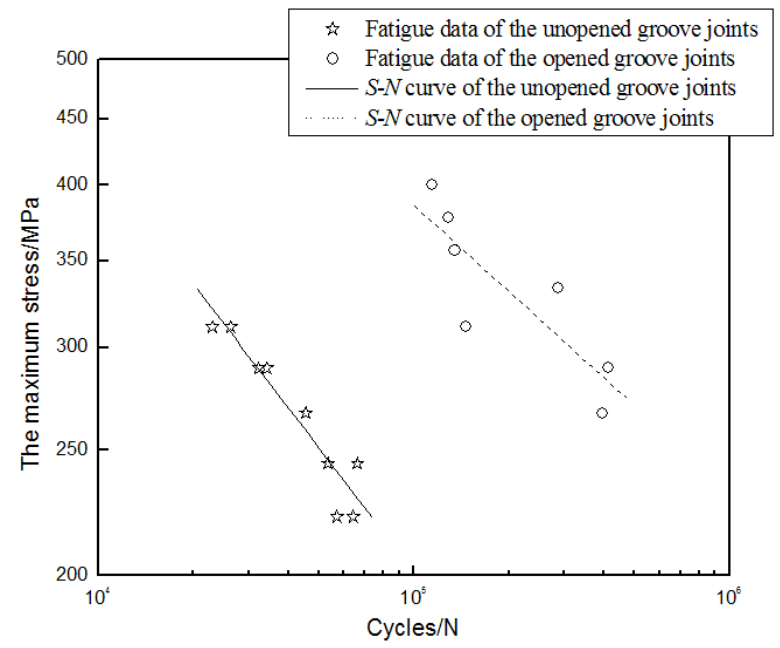

Fig. 3. The fatigue $S-N$ curve of opened groove joints and unopened groove joints

For the unopened groove joints, we selected the typical fatigue fracture location to observe and analyze. The position of fracture at weld root where the unfused toot exsits. The fatigue crack source is completely from the weld root (see Fig. 4(a)). As for the opened groove joints, another kind of fatigue fracture is caused by the stress concentration at the weld toe (Fig. 4(b)).

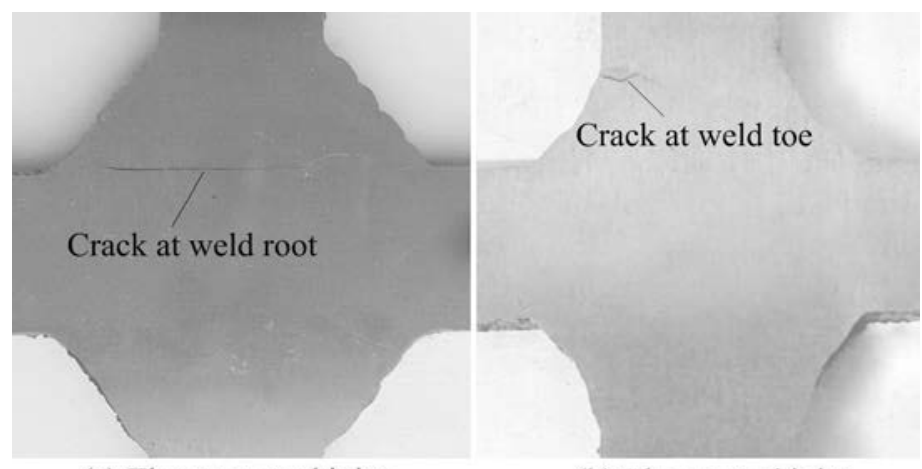

$\begin{array}{ll}\text { (a) The unopened joint } & \text { (b) The opened joint }\end{array}$

Fig. 4. The position of faitgue fracture of the unopened joint and the opened joint

As we can see from Fig. 4, after the treatment of opening groove, the fatigue crack source mainly form at weld toe where the stress concentration is very serious. Although the root position still has some defects (caused by operation of the staffs or groove size), it is not enough to form the fatigue crack source.

In addition, the crack initiation with an arrow (Fig. 5(a)) originates from the unfused toot between base metal and weld rather than weld toe. Because non-fusion region exists in the bond zone between base metal and weld. Fig. 5(b) indicates that the growth of microscopic crack is unsteady and fatigue striation is discontinuous. The deeper cracks traverse the slip planes within each grain. There is no the obvious fatigue striations. It is because that the texture of weld metal is not heterogeneous, which leads to the irregular crack growth.

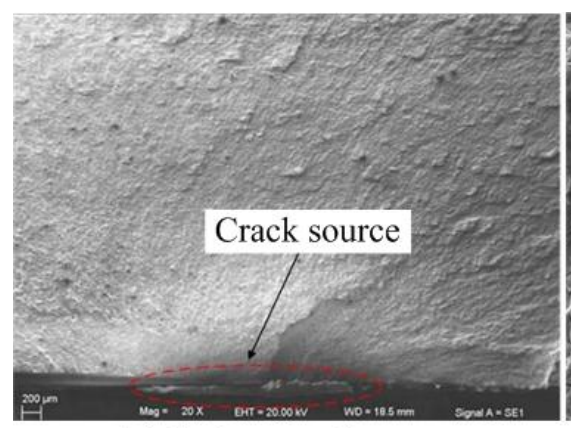

(a) Fatigue crack source

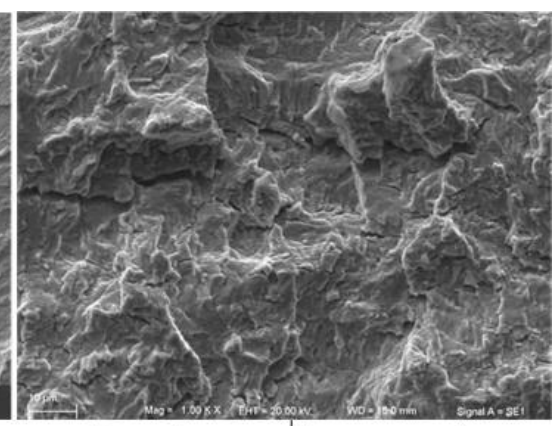

(b) Fatigue crack propagation

Fig. 5. Fatigue fracture characteristics of the unopened joints 
The crack initiation with an arrow (Fig. 6(a)) originates from the edge imperfections at weld toe due to the serious stress concentration. In the fatigue crack propagation regime, the growth of microscopic crack is stable and there is no larger and deeper crack along grain boundaries. The reason is that crack grows along homogeneous base metal (Fig. 6(b)).

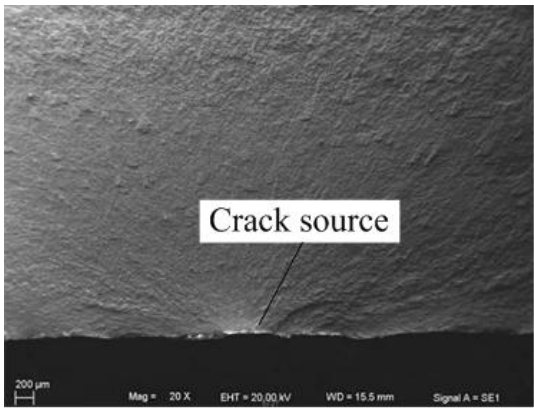

(a) Fatigue crack source

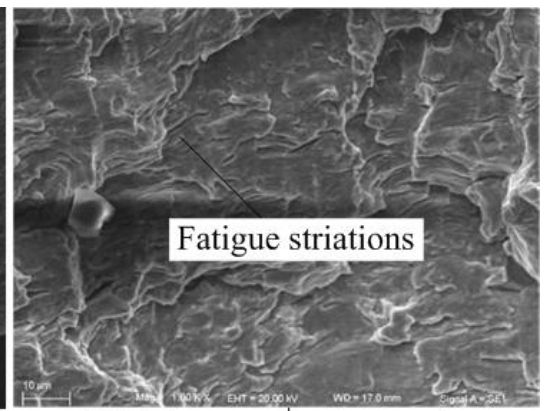

(b) Fatigue crack propagation

Fig. 6. Fatigue fracture characteristics of the opened joints

\section{Summary}

By analyzing the structure characteristics of hydraulic bracket, we know that the improvement of fatigue performance of welding structure is the interact result of designing and subsequent processing. The designing method and scheme are the basic factors to determine fatigue life. The key point of fatigue design of the welding structure is to avoid or reduce stress concentration.

\section{Acknowledgement}

This project is supported by National Natural Science Foundation of China (Grant No. 51305160). and the China Postdoctoral Science Foundation-China through Grant No. 2014M550172.

\section{References}

[1] Zheng Xiaowen, Zhang Heng, Liu Jinlong, An Xuliang, Fatigue life analysis of hydraulic support based on FEM. Mining Machine, 2010 38(17) 7-10.

[2] Wu Lebing, The Development and Outlook of Hydraulic Support. Journal of Huinan Vocational \& Technical College, 2006 6(18) 44-45.

[3] Huo Lixing, The fracture behavior and evaluation of the welding structure. Beijing: Machinery Industry Press, 2000.

[4] Qian Qiang, Training materials of IWE, the third section. The structure and design of welding, 2013.

[5] Tian Xitang, The welding structure. Beijing: Machinery Industry Press, 1982 